Genome Insight

Genomics and Bioinformatics

\title{
Complete chloroplast genome sequence of Caryocar brasiliense Camb. (Caryocaraceae) and comparative analysis brings new insights into the plastome evolution of Malpighiales
}

\author{
Rhewter Nunes ${ }^{1}$ (iD , Ueric José Borges de Souza ${ }^{1}$ iD , Cintia Pelegrineti Targueta ${ }^{1}$ iD, Rafael Barbosa \\ Pinto $^{1}$ (iD), Thannya Nascimento Soares ${ }^{1}$ (iD), José Alexandre Felizola Diniz-Filho ${ }^{2}$ (D) and Mariana Pires de \\ Campos Telles ${ }^{1,3}$ iD \\ ${ }^{1}$ Universidade Federal de Goiás (UFG), Instituto de Ciências Biológicas, Laboratório de Genética e \\ Biodiversidade (LGBio), Goiânia, GO, Brazil. \\ ${ }^{2}$ Universidade Federal de Goiás (UFG), Instituto de Ciências Biológicas, Laboratório de Ecologia Teórica e \\ Sintese (LETS), Goiânia, GO, Brazil. \\ ${ }^{3}$ Pontifícia Universidade Católica (PUC - GO), Escola de Ciências Agrárias e Biológicas, Goiânia, GO, \\ Brazil.
}

\begin{abstract}
Caryocar brasiliense (Caryocaraceae) is a Neotropical tree species widely distributed in Brazilian Savannas. This species is very popular in central Brazil mainly by the use of its fruits in the local cuisine, and indeed it is one of the candidates, among Brazilian native plants, for fast track incorporation into cropping systems. Here we sequenced the complete chloroplast genome of $C$. brasiliense and used the data to access its genomic resources using highthroughput sequencing. The chloroplast exhibits a genome length of $165,793 \mathrm{bp}$ and the typical angiosperm quadripartite structure with two copies of an inverted repeat sequence (IRa and IRb) of 34,902 bp each, separating a small single copy (SSC) region of 11,852 bp and a large single copy (LSC) region of 84,137 bp. The annotation analysis identified 136 genes being 87 protein-coding, eight rRNA and 37 tRNA genes. We identified 49 repetitive DNA elements and 85 microsatellites. A bayesian phylogenetic analysis helped to understand previously unresolved relationships in Malpighiales, placing Caryocaraceae as a separated group in the order, with high supported nodes. This study synthetizes valuable information for further studies allowing a better understanding of evolutionary patterns in the group and providing resources for future breeding programs.
\end{abstract}

Keywords: Cerrado, genomics, molecular evolution, organellar genome, genome evolution.

Received: May 23, 2019; Accepted: February 14, 2020.

In the order, Malpighiales, the family Caryocaraceae has not yet been explored using genomic approaches. Caryocaraceae represents a poorly resolved group within Malpighiales, forming a polytomy with other families, such as Malpighiaceae and Chrysobalanaceae, for which we have fully sequenced chloroplast genomes at the species level (Xi et al., 2012; Angiosperm Phylogeny Group et al., 2016). The main representatives of the Caryocaraceae family are the species of the genus Caryocar L., in particular Caryocar brasiliense Camb. This species is a Neotropical tree, the fruit of which is highly valued in Brazilian cuisine, a nutritious source for bats (Gribel and Hay, 1993), and is widely known in folk culture as a symbol of Brazilian sa-

Send correspondence to Rhewter Nunes. Universidade Federal de Goiás (UFG), Instituto de Ciências Biológicas, Laboratório de Genética e Biodiversidade (LGBio), 74690-900, Goiânia, GO, Brazil. E-mail: rhewter@gmail.com. vannas (or Cerrado) (Gribel and Hay, 1993; Araujo, 1995). The fruit pulp of $C$. brasiliense is rich in unsaturated fatty acids, vitamins, and phenolic acids, as well in carotenoids, such as violaxanthin, lutein, and zeaxanthin (Castro et al., 2008; Mariano et al., 2009). Because of all these characteristics, $C$. brasiliense is one of the main native Cerrado species that is a candidate for incorporation into cropping systems (Leite et al., 2006; Tunholi et al., 2013).

Despite the importance of Caryocar brasiliense, until now no genomic resources have been developed for this species. A few studies have used microsatellite markers or short sequences to evaluate the genetic diversity patterns of this species, showing that the natural populations of $C$. brasiliense have a relatively low genetic structure and a high genetic and phylogeographic diversity (e.g. DinizFilho et al., 2009; Collevatti et al., 2011). Thus, in this study, we sequenced the complete chloroplast genome of C. brasiliense and used the data to access its genomic re- 
sources using high-throughput sequencing. As a result, we generated information regarding the chloroplast genome sequence, gene composition and organization, and repeat sequences using part of our data to reconstruct a phylogenetic tree for the Malpighiales order to analyze the relationships of $C$. brasiliense within this group.

The total DNA of the fresh leaves of Caryocar brasiliense was extracted using the CTAB protocol (Doyle and Doyle, 1987). The sample was sequenced using an Illumina HiSeq2000 platform in paired-end $2100 \mathrm{bp}$ mode. Raw reads were evaluated for base quality sequencing and the presence of sequencing adapters using FastQC software (Andrews, 2010). Quality control was performed using Trimmomatic (Bolger et al., 2014) software. The resulting high-quality reads were selected for de novo chloroplast genome assembly using NOVOPlasty v.2.7.1 software (Dierckxsens et al., 2017). We performed gene annotation of the Caryocar brasiliense chloroplast genome using CHLOROBOX GeSeq (Tillich et al., 2017) and Dual Organellar GenoMe Annotator (DOGMA) (Wyman et al., 2004) software. Simple sequence repeats (SSR) or microsatellite regions were predicted in the $C$. brasiliense chloroplast genome using Imperfect Microsatellite Extractor (IMEx) (Mudunuri and Nagarajaram, 2007). Repeat sequence elements were predicted using REPuter software (Kurtz, 2002). In addition, we performed a Bayesian phylogenetic analysis for several Malpighiales species using 76 protein-coding gene sequences. For a detailed description of the methods, please refer to the Supplementary Material.

The complete sequence of the Caryocar brasiliense chloroplast genome was deposited in the GenBank database (accession number: MK726375) with a high mean genome coverage $(715 \mathrm{X})$. The plastome of $C$. brasiliense exhibited a total length of 165,793 bp and typical quadripartite division, which has previously been observed in other flowering plants (Figure 1; Figure S1). The genome was comprised of a large single copy (LSC), a small single copy (SSC), and a pair of inverted repeats (IRa and IRb). These regions were comprised of $84,137 \mathrm{bp}, 11,852 \mathrm{bp}$, and $34,902 \mathrm{bp}$, respectively, with a GC content of $36.7 \%$. The IR regions exhibited the greatest GC content (39.6\%), followed by LSC (35.0\%) and SSC (31.5\%). Within the inverted repeat regions, the $\mathrm{GC}$ content was higher where the rRNAs were predicted.

We compared the structural features of the C. brasiliense chloroplast genome with another nine chloroplast genomes from nine other families in the Malpighiales order. In comparison, $C$. brasiliense had the largest genome size, with large IR regions, but one of the smallest small single copies regions, along with Linum usitatissimum L. (Souza et al., 2017) (Table 1). However, C. brasiliense showed a similar size with respect to the LSC region of other species. This may be explained by the fact that many of the photosynthetic genes are present in this region, and are therefore important for the persistence of these species, resulting in fewer contraction/expansion events in the region of the chloroplast genome.

We found 115 different genes in the genome, of which 77 were protein-coding genes, four ribosomal RNAs, 30 transfer RNAs, and four pseudogenes (Table $\mathrm{S} 1$ ). In addition, 10 protein-coding genes, four rRNAs, and seven tRNAs were found to be duplicated. Three of these tRNA genes, namely $\operatorname{trn} A-U G C$, trnM-CAU, and trnR$A C G$, were found to have more than one copy in the genome (each gene appeared four times). As such, taking into consideration these duplicated genes, the C. brasiliense chloroplast genome had a total of 136 genes (87 proteincoding genes, four pseudogenes, eight rRNAs, and 37 tRNAs). We also observed 10 genes that contained introns. Over all, C. brasiliense was found to have a relatively conserved number of genes compared to the other Malpighiales species, especially in terms of the genes related to rRNA, tRNA, and photosynthesis. The gene features of $C$. brasiliense were very similar to those of Byrsonima coccolobifolia Kunth (Menezes et al., 2018), another Malpighiales species (Table S2).

The pseudogenes predicted in the $C$. brasiliense chloroplast genome were $n d h H, p s a A, p s a B$, and $p s b A$. These pseudogenes had a copy of the gene in the complete form and are supposedly involved in the structural changes of the chloroplast genome in $C$. brasiliense. For example, the $n d h H$ pseudogene was related to the process of duplication of the Inverted Repeat region, while the others pseudogenes were related to the inversion events in the Large Single Copy region, generating variation in the order of the plastid genes in comparison to the chloroplast genomes of other Malpighiales species. Such inversion events were also observed in the chloroplast genome of Passiflora edulis Sims, another Malpighiales species (Cauz-Santos et al., 2017), which is indicative of a non-conservative gene collinearity found in all members of this order.

A comparative analysis with 10 Malpighiales species revealed a highly conserved pattern of variation within the genomes (highly variable regions between $C$. brasiliense and Jatropha curcas were also very variable in other species compared to J. curcas), with highly conserved protein-coding genes, as well as intergenic regions with more variation (Figure S2). Passiflora edulis had the highest divergent regions in comparison to Jatropha curcas L. and other species, with a similarity between regions of less than $50 \%$.

Compared to other species under analysis, Caryocar brasiliense displayed one of the smallest Small Single Copy (SSC) regions and the largest Inverted Repeat (IR) regions. This indicates that the size of these regions evolves differently between different species of Malpighiales (Mower et al., 2015). We performed an IR boundaries comparison analysis to determine the genes present at the sites that separate the chloroplast regions (Figure 2). The most common gene to flank the region between the IR and SSC was 


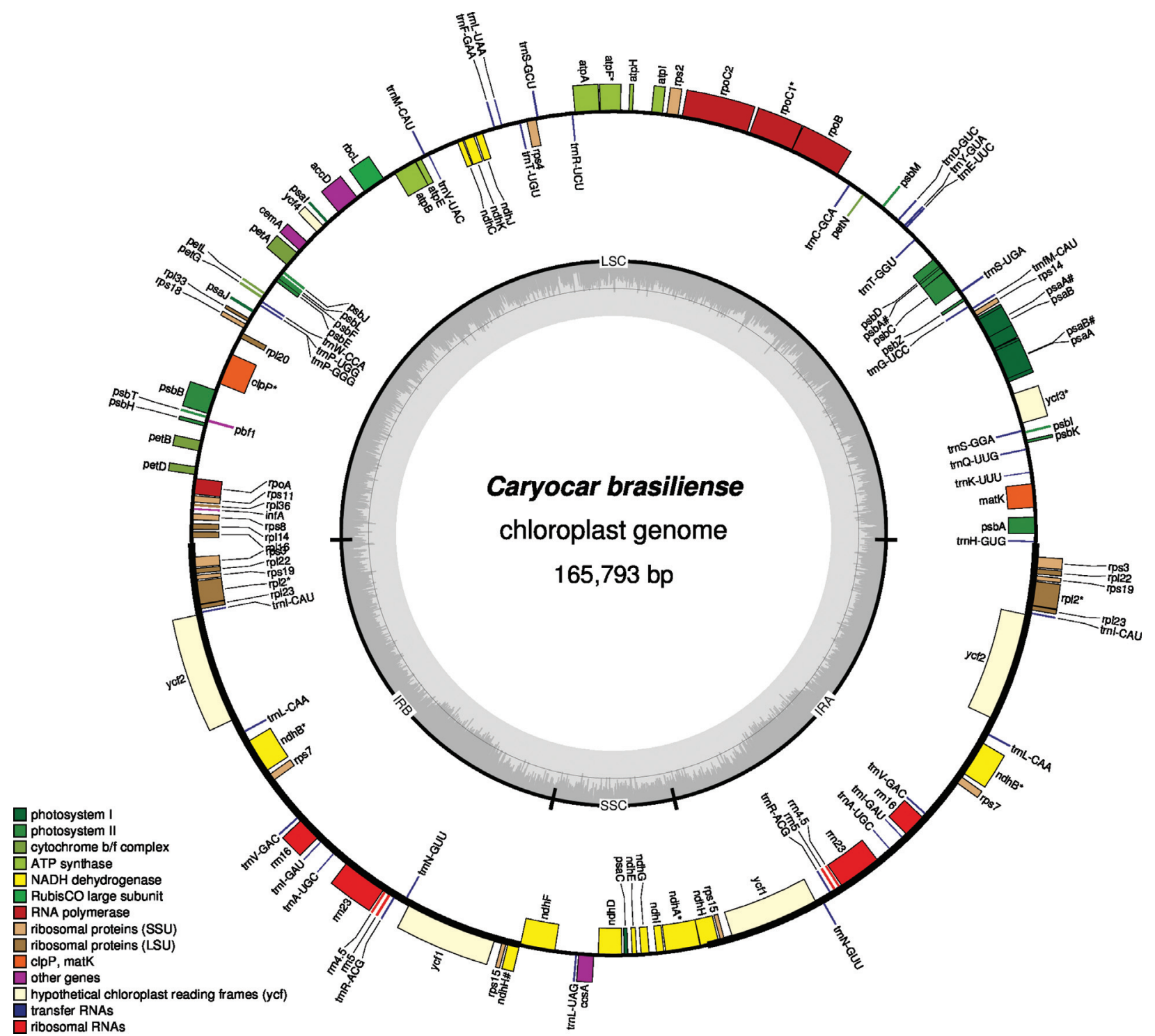

Figure 1 - Chloroplast genome map of Caryocar brasiliense. The genes drawn outside and inside of the circle are transcribed in clockwise and counterclockwise directions, respectively. Genes were colored based on their functional groups. The inner circle shows the quadripartite structure of the chloroplast: small single copy (SSC), large single copy (LSC) and a pair of inverted repeats (IRa and IRb). The gray ring marks the GC content with the inner circle marking a 50\% threshold. Genes that have introns were marked with “*” and pseudogenes were marked with "\#”.

Table 1 - Comparative chloroplast genome structural features in 10 species from Malpighiales order. LSC: Large Single Copy region; SSC: Small Single Copy region; IR: Inverted Repeats regions and bp: base pair.

\begin{tabular}{|c|c|c|c|c|c|c|}
\hline Species & Family & Genome size (bp) & LSC (bp) & $\mathrm{SSC}(\mathrm{bp})$ & IR (bp) & $\mathrm{GC}(\%)$ \\
\hline Caryocar brasiliense & Caryocaraceae & 165,793 & 84,137 & 11,852 & 34,902 & 36.7 \\
\hline Garcinia mangostana & Clusiaceae & 158,179 & 86,458 & 17,703 & 27,009 & 36.1 \\
\hline Chrysobalanus icaco & Chrysobalanaceae & 163,937 & 89,188 & 19,817 & 26,885 & 36.2 \\
\hline Erythroxylum novogranatense & Erythroxylaceae & 163,937 & 91,384 & 18,137 & 27,208 & 35.9 \\
\hline Manihot esculenta & Euphorbiaceae & 161,453 & 89,295 & 18,250 & 26,954 & 35.9 \\
\hline Linum usitatissimum & Linaceae & 156,721 & 81,767 & 10,974 & 31,990 & 37.5 \\
\hline Byrsonima coccolobifolia & Malpighiaceae & 160,329 & 88,524 & 17,833 & 26,986 & 36.8 \\
\hline Passiflora edulis & Passifloraceae & 151,406 & 85,720 & 13,378 & 26,154 & 37.0 \\
\hline Populus tremula & Salicaceae & 156,067 & 84,367 & 16,670 & 27,509 & 36.8 \\
\hline Viola seoulensis & Violaceae & 156,507 & 85,691 & 18,008 & 26,404 & 36.3 \\
\hline
\end{tabular}




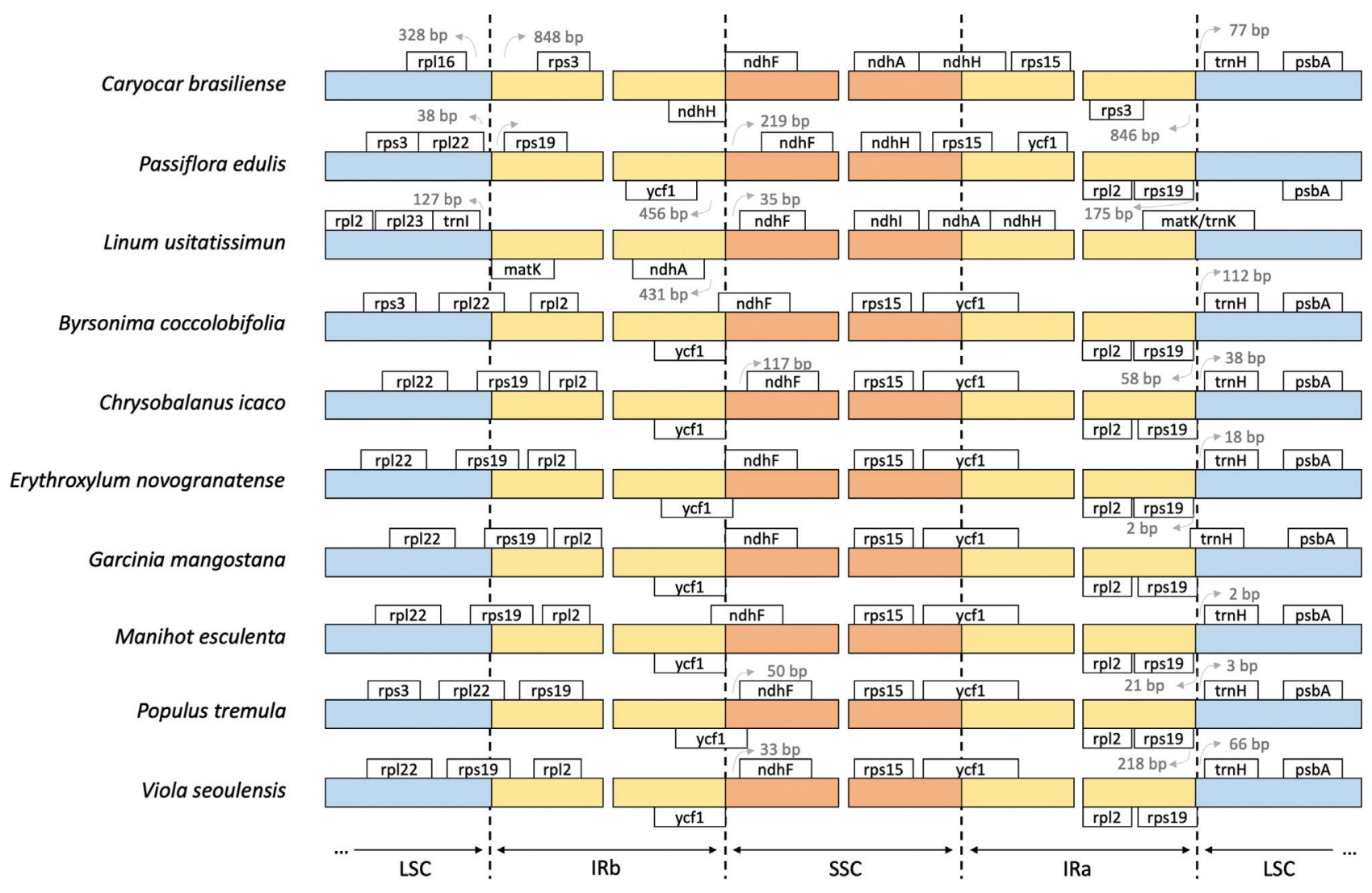

Figure 2 - Comparison of the junctions involving Inverted Repeat (IRa and IRb) regions with Large Single Copy (LSC) and Small Single Copy (SSC) regions among 10 chloroplast genomes of Malpighiales. The IR regions are represented in yellow whereas LSC and SSC in blue and orange, respectively. The white boxes represent the genes present in each region. The arrows represent the distance (in base pairs) of genes from the junction site between regions.

$y c f 1$ in seven of the ten species analyzed. Commonly, $y c f 1$ and $y c f 1$ pseudogene were present in the IR/SSC boundaries in Malpighiales species, such as Byrsonima coccolobifolia (Menezes et al., 2018), Chrysobalanus icaco L. (Bardon et al., 2016), Erythroxylum novogranatense (D. Morris) Hieron. (unpublished), Garcinia mangostana L. (Jo et al., 2017), Manihot esculenta Crantz (Daniell et al., 2008), Populus tremula L. (Kersten et al., 2016), and Viola seoulensis Nakai (Cheon et al., 2017).

Three of the species which were subjected to analysis did not have $y c f l$ as a flanking gene of the IR/SSC region, Caryocar brasiliense, Passiflora edulis (Cauz-Santos et al., 2017), and Linum usitatissimum L. (Souza et al., 2017). Caryocar brasiliense had a boundary between the IR/SSC region, flanked by $n d h H$ and $n d h H$ pseudogene, while in $P$. edulis, rps 15 and intergenic region $y c f 1-n d h F$ were found. For L. usitatissimum, $n d h A$ and the intergenic region $n d h A-n d h F$ were observed. The IR/SSC boundary region was found to have a high collinearity between different genomes. The order of the conserved genes was as follows: $n d h A, n d h H, r p s 15$, and $y c f 1$ for all species under analysis. Meanwhile, the bounder of IR/SSC for the major species included $y c f 1$, however, in some Malpighiales species, this site was displaced with the donation of genomic segments from the SSC region to the IR regions. In addition to colinear genetic evidence, this pattern of expansion of the IR regions with the contraction of the SSC region was also supported by the region lengths, which indicated that species with no $y c f 1$ flanking the IR/SSC boundery had a smaller SSC region (Table S2).

A total of 85 perfect microsatellites (SSRs) were identified in the Caryocar brasiliense chloroplast genome sequence (Figure S3). With respect to the repeat motif, we found 52 mononucleotides, 11 dinucleotides, five trinucleotides, 12 tetranucleotides, three pentanucleotides, and two hexanucleotides. The number of continuous repeats (motif iterations) ranged from 3 to 16 (Table S3). The chloroplast region with the highest number of SSRs were LSC (56.47\%), followed by IR (29.41\%) and SSC (14.12\%). SSRs are important regions because they serve as molecular markers in studies on genetic diversity, phylogeny, and phylogeography for Brazilian Savanna species (Rabelo et al., 2011; Soares et al., 2012; Telles et al., 2013). The SSR regions identified can be used in molecular marker development testing for genetic diversity studies of $C$. brasiliense and related species (Table $\mathrm{S} 4$ ).

We also identified repeat sequences in the C. brasiliense chloroplast genome and another 10 species from the 


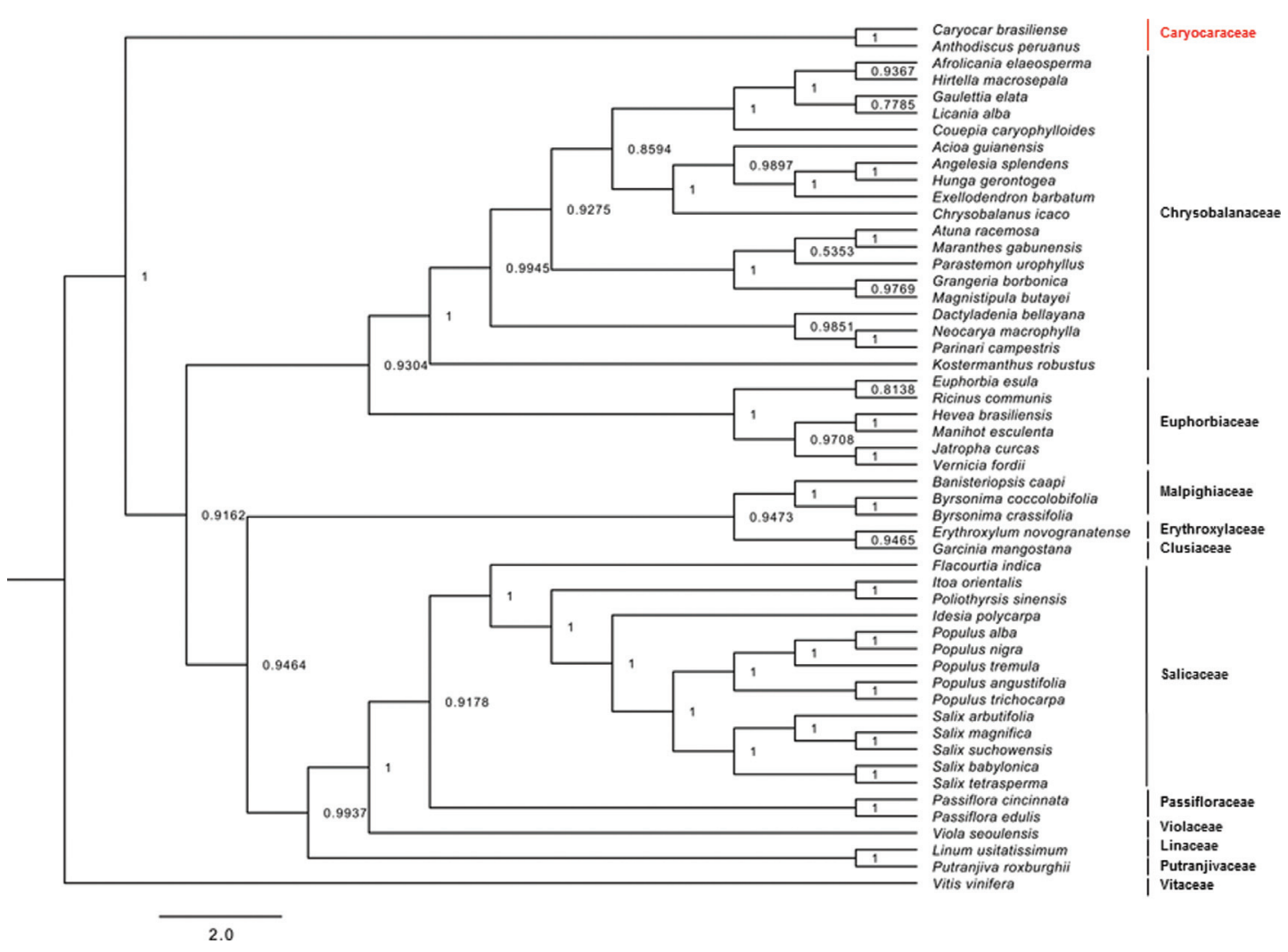

Figure 3 - Phylogenetic tree reconstruction based on 52 taxa using Bayesian inference based on 76 protein-coding chloroplast genes. Numbers represent the Bayesian posterior probability given to each node. The bars on the right represents the botanic families of species.

Malpighiales order (chloroplast genome subset described in Material and Methods) (Table S5). We observed a total of 49 repeats in $C$. brasiliense. With regards to the type of repeat, we found 18 forward, 30 palindromic, and one reverse repeat. No repeats of the complement type were observed in $C$. brasiliense. Complement repeats only occurred in three of the 10 species in analysis: one in Chrysobalanus icaco, two in Erythroxylum novogranatense, and one in Viola seoulensis. In another three species, Linum usitatissimum, Manihot esculenta, and Passiflora edulis, we only found forward and palindromic repeats. Repeat analysis revealed a highly conserved total number of repeats within the Malpighiales order, although the type of repeats varied across species.

We performed a phylogenetic analysis by sampling 52 representatives from all the families in the Malpighiales order with sequenced chloroplast genomes using proteincoding gene sequences (Table S6). Additionally, we also retrieved chloroplast gene sequences from Anthodiscus peruanus Baill. (Caryocaraceae) and Putranjiva roxburghii Wall. (Putranjivaceae). This analysis resulted in a phylogenetic tree with high supported values for the nodes, with a Bayesian posterior probability given to each one (Figure 3). As expected, all the species analyzed (including C. brasiliense) fell within the clades that represent their respective botanical families, validating the chloroplast sequences obtained in this study.
The currently accepted phylogeny for the order Malpighiales displays a polytomy involving Caryocaraceae, Putranjivoid, Malpighioid, and Chrysobalanoid species (Angiosperm Phylogeny Group et al., 2003; Xi et al., 2012). Here, for the first time, a highly supported phylogenetic tree identified Caryocaraceae as a sister clade in relation to the other families within Malpighiales (Figure 3). Moreover, this result provides evidence that reinforces the non-clustering among Caryocaraceae, Linaceae, and Erythroxylaceae within the same clade, as discussed in a previous study (Soltis et al., 2007). The current phylogeny of this group was investigated using several genes. The novel genomic resources produced in this study will help to improve our understanding of the phylogenetic relationships among species in the order Malpighiales (Angiosperm Phylogeny Group et al., 2003; Angiosperm Phylogeny Group et al., 2009; Xi et al., 2012; Angiosperm Phylogeny Group et al., 2016). These resources will help to resolve the problem of uncertain clades. This study demonstrates how the use of high-throughput sequencing technologies can increase the accuracy of phylogenetic analysis. Moreover, the data provided here serve as a novel genetic and genomic resource for Malpighiales and offer the first complete genome sequence and chloroplast content in the Caryocaraceae family. 


\section{Acknowledgments}

The authors thanks to Ariany Rosa Gonçalves for the help in DNA extraction process. This work was developed in the context of the National Institutes for Science and Technology in Ecology, Evolution and Biodiversity Conservation (INCT - EECBio), supported by MCTIC/CNPq (process \#465610/2014-5) and Foundation for Research Support of the State of Goiás (FAPEG), in addition to support from PPGS CAPES/FAPEG (Public Call \#08/2014) and National Council for Scientific and Technological Development (CNPq) (Call MCTIC/CNPq \#28/2018, process 435477/2018-8). R.N. and U.J.B.S. were supported by doctoral fellowships from Coordination for the Improvement of Higher Education Personnel (CAPES). T.N.S., J.A.F.D.F. and M.P.C.T. were supported by productivity fellowships from CNPq.

\section{Conflict of Interest}

The authors declare that there is no conflict of interest that could be perceived as prejudicial to the impartiality of the reported research.

\section{Authors Contributions}

RN, TNS, JAFDF and MPCT conceived the study, RN, UJBS, CPT, RBP and TNS conducted the experiments, RN and UJBS analyzed the data, RN wrote the manuscript, all authors read and approved the final version.

\section{References}

Andrews S (2010) FastQC: a quality control tool for high throughput sequence data, http://www.bioinformatics.babraham.ac.uk/projects/fastqc.

Angiosperm Phylogeny Group, Bremer B, Bremer K, Chase MW, Reveal JL, Soltis DE, Soltis PS and Stevens PF (2003) An update of the Angiosperm Phylogeny Group classification for the orders and families of flowering plants: APG II. Bot J Linn Soc 141:399-436.

Angiosperm Phylogeny Group, Bremer B, Bremer K, Chase MW, Fay MF, Reveal JL, Soltis DE, Soltis PS and Stevens PF (2009) An update of the Angiosperm Phylogeny Group classification for the orders and families of flowering plants: APG III. Bot J Linn Soc 161:105-121.

Angiosperm Phylogeny Group, Chase MW, Christenhusz MJM, Fay MF, Byng JW, Judd WS, Soltis DE, Mabberley DJ, Sennikov AN, Soltis PS et al. (2016) An update of the Angiosperm Phylogeny Group classification for the orders and families of flowering plants: APG IV. Bot J Linn Soc 181:1-20.

Araujo FD (1995) A review of Caryocar brasiliense (Caryocaraceae) - an economically valuable species of the central Brazilian cerrados. Econ Bot 49:40-48.

Bardon L, Sothers C, Prance GT, Malé PJG, Xi Z, Davis CC, Murienne J, García-Villacorta R, Coissac E, Lavergne S et al. (2016) Unraveling the biogeographical history of chrysobalanaceae from plastid genomes. Am J Bot 103:1089-1102.
Bolger AM, Lohse M and Usadel B (2014) Trimmomatic: A flexible trimmer for Illumina sequence data. Bioinformatics 30:2114-2120.

Castro AJ, Grisolia CK, Araújo BC, Dias CD, Dutra ES and Nepomuceno JC (2008) Recombinogenic effects of the aqueous extract of pulp from pequi fruit (Caryocar brasiliense) on somatic cells of Drosophila melanogaster. Genet Mol Res 7:1375-1383.

Cauz-Santos LA, Munhoz CF, Rodde N, Cauet S, Santos AA, Penha HA, Dornelas MC, Varani AM, Oliveira GCX, Bergès $\mathrm{H}$ et al. (2017) The chloroplast genome of Passiflora edulis (Passifloraceae) assembled from long sequence reads: Structural organization and phylogenomic studies in Malpighiales. Front Plant Sci 8:1-17.

Cheon KS, Yang JC, Kim KA, Jang SK and Yoo KO (2017) The first complete chloroplast genome sequence from Violaceae (Viola seoulensis). Mitochondrial DNA Part A 28:67-68.

Collevatti RG, Nabout JC and Diniz-Filho JAF (2011) Range shift and loss of genetic diversity under climate change in Caryocar brasiliense, a Neotropical tree species. Tree Genet Genomes 7:1237-1247.

Daniell H, Wurdack KJ, Kanagaraj A, Lee S, Saski C and Jansen RK (2008) The complete nucleotide sequence of the cassava (Manihot esculenta) chloroplast genome and the evolution of atpF in Malpighiales: RNA editing and multiple losses of a group II intron. Theor Appl Genet 116:723-737.

de Santana Lopes A, Pacheco TG, Santos KGD, Vieira LDN, Guerra MP, Nodari RO, de Souza EM, de Oliveira Pedrosa F and Rogalski M (2017) The Linum usitatissimum L. plastome reveals atypical structural evolution, new editing sites, and the phylogenetic position of Linaceae within Malpighiales. Plant Cell Rep 37:307-328.

Dierckxsens N, Mardulyn P and Smits G (2017) NOVOPlasty: De novo assembly of organelle genomes from whole genome data. Nucleic Acids Res 45:e18.

Diniz-Filho JAF, Nabout JC, Bini LM, Soares TN, Campus Telles MP, Marco P and Collevatti RG (2009) Niche modelling and landscape genetics of Caryocar brasiliense ("Pequi" tree: Caryocaraceae) in Brazilian Cerrado: An integrative approach for evaluating central-peripheral population patterns. Tree Genet Genomes 5:617-627.

Doyle JJ and Doyle JL (1987) A rapid DNA isolation procedure for small quantities of fresh leaf tissue. Phytolog Bull 19:11-15.

Gribel R and Hay JD (1993) Pollination ecology of Caryocar brasiliense (Caryocaraceae) in Central Brazil cerrado vegetation. J Trop Ecol 9:199-211.

Jo S, Kim HW, Kim YK, Sohn JY, Cheon SH and Kim KJ (2017) The complete plastome of tropical fruit Garcinia mangostana (Clusiaceae). Mitochondrial DNA Part B Resour 2:722-724.

Kersten B, Faivre Rampant P, Mader M, Le Paslier MC, Bounon R, Berard A, Vettori C, Schroeder H, Leplé JC and Fladung M (2016) Genome sequences of Populus tremula chloroplast and mitochondrion: Implications for holistic poplar breeding. PLoS One 11:e0147209.

Kurtz S (2002) REPuter: the manifold applications of repeat analysis on a genomic scale. Nucleic Acids Res 29:4633-4642.

Leite GLD, Veloso VSR, Zanuncio JC, Fernandes LA and Almeida CIM (2006) Phenology of Caryocar brasiliense in the Brazilian cerrado region. For Ecol Manage 236:286-294. 
Mariano RG de B, Couri S and Freitas SP (2009) Enzymatic technology to improve oil extraction from Caryocar brasiliense camb. (Pequi) Pulp. Rev Bras Frutic 31:637-643.

Menezes APA, Resende-Moreira LC, Buzatti RSO, Nazareno AG, Carlsen M, Lobo FP, Kalapothakis E and Lovato MB (2018) Chloroplast genomes of Byrsonima species (Malpighiaceae): comparative analysis and screening of high divergence sequences. Sci Rep 8:2210.

Mower JP, Zhu A, Guo W, Fan W and Gupta S (2015) Evolutionary dynamics of the plastid inverted repeat: the effects of expansion, contraction, and loss on substitution rates. New Phytol 209:1747-1756.

Mudunuri SB and Nagarajaram HA (2007) IMEx: Imperfect microsatellite extractor. Bioinformatics 23:1181-1187.

Rabelo SG, Teixeira CF, Telles MPC and Collevatti RG (2011) Development and characterization of microsatellite markers for Lychnophora ericoides, an endangered Cerrado shrub species. Conserv Genet Resour 3:741-743.

Soares TN, Melo DB, Resende LV, Vianello RP, Chaves LJ, Collevatti RG and Telles MP (2012) Development of microsatellite markers for the neotropical tree species Dipteryx alata (Fabaceae). Am J Bot 99:e72-e73.

Soltis DE, Gitzendanner MA and Soltis PS (2007) A 567-taxon data set for angiosperms: The challenges posed by Bayesian analyses of large data sets. Int J Plant Sci 168:137-157.

Telles MPC, Silva JB, Resende LV, Vianello RP, Chaves LJ, Soares TN and Collevatti RG (2013) Development and characterization of new microsatellites for Eugenia dysenterica DC (Myrtaceae). Genet Mol Res 12:3124-3127.

Tillich M, Lehwark P, Pellizzer T, Ulbricht-Jones ES, Fischer A, Bock R and Greiner S (2017) GeSeq - Versatile and accurate annotation of organelle genomes. Nucleic Acids Res 45:W6-W11.

Tunholi VP, Ramos MA and Scariot A (2013) Availability and use of woody plants in a agrarian reform settlement in the cerrado of the state of Goiás, Brazil. Acta Bot Bras 27:604612 .
Wyman SK, Jansen RK and Boore JL (2004) Automatic annotation of organellar genomes with DOGMA. Bioinformatics 20:3252-3255.

Xi Z, Ruhfel BR, Schaefer H, Amorim AM, Sugumaran M, Wurdack KJ, Endress PK, Matthews ML, Stevens PF, Mathews S et al. (2012) Phylogenomics and a posteriori data partitioning resolve the Cretaceous angiosperm radiation Malpighiales. Proc Natl Acad Sci 109:17519-17524.

\section{Supplementary Material}

The following online material is available for this article:

Figure S1 - Distribution of k-mers in Caryocar brasiliense chloroplast genome.

Figure S2 - Alignment view of chloroplast genomes of Malpighiales order using Jatropha curcas (Euphorbiaceae) as reference.

Figure S3 - Repeat and comparative analysis in Caryocar brasiliense chloroplast genome.

Table S1 - Gene content and classification of Caryocar brasiliense chloroplast genome.

Table S2 - Comparative chloroplast genome gene features in 10 species from Malpighiales order.

Table S3 - Frequency of types of simple sequence repeats based on its motif length in Caryocar brasiliense chloroplast genome.

Table S4 - Simple sequence repeats identified in Caryocar brasiliense chloroplast genome sequence.

Table S5 - Species list used in comparative analysis of Malpighiales order chloroplast genomes.

Table S6 - Species list used in phylogenetic analysis of Malpighiales order.

Method details.

Associate Editor: Ana Tereza Vasconcelos

License information: This is an open-access article distributed under the terms of the Creative Commons Attribution License (type CC-BY), which permits unrestricted use, distribution and reproduction in any medium, provided the original article is properly cited. 